\title{
Las mujeres de las fronteras americanas en la expedición científica de Jean- François de Galaup. Santa Catarina, Concepción y Monterrey (siglo XVIII)*
}

\section{Resumen}

El viaje de circunnavegación encabezado por Jean-François de Galaup, conde de la Pérouse (1785-1788) se enmarca en las expediciones científicas a América en el XVIII. A través del análisis historiográfico, este artículo analiza las representaciones que La Pérouse dejó asentadas en sus diarios de viaje sobre las mujeres mestizas, criollas e indígenas que habitaban en tres distintas regiones de frontera: la isla de Santa Catarina en Brasil; la Bahía de la Concepción en Chile y Monterrey en California. En tanto las mujeres no fueron concebidas por los viajeros ilustrados como un objeto de observación en sí mismo, los indicios encontrados se encuentran vinculados a la descripción de prácticas ligadas al trabajo femenino, al ámbito doméstico y familiar o a la sexualidad y a transgresiones denunciadas por la mirada masculina. A partir del cotejo entre los distintos espacios es posible distinguir los desiguales márgenes de acción de las mujeres en estos espacios.

\section{Palabras clave}

Tesauro: mujer, expedición científica, frontera

Autor: siglo XVIII, Jean-François de Galaup, conde de la Pérouse

Referencia bibliográfica para citar este artículo: Perez Gerardo, Diana Roselly. "Las mujeres de las fronteras americanas en la expedición científica de Jean-François de Galaup. Santa Catarina, Concepción y Monterrey (siglo XVIII)”. Anuario de Historia Regional y de las Fronteras 26.2 (2021): 225-254.

Fecha de recepción: 30/11/2020

Fecha de aceptación: 18/03/2021

Diana Roselly Pérez Gerardo: Doctora en Historia. Investigadora del Instituto de Investigaciones Históricas de la Universidad Nacional Autónoma de México. Código ORCID: 0000-0001-6777-3081. Correo electrónico: dianaroselly@unam.mx.

\footnotetext{
* Esta investigación forma parte del proyecto de investigación: Los márgenes en el centro. El mundo indiano a través de sus fronteras.
} 


\title{
The Women of the American Frontiers in the Cientific Expedition of Jean-François de Galaup: Santa Catarina, Concepción and Monterrey (Eighteenth-century)
}

\begin{abstract}
The circumnavigation voyage led by Jean-François de Galaup, count de la Pérouse (1785-1788) is one of the scientific expeditions sent to America in the Eighteenthcentury. Through the analysis of his travel diaries, this article focuses on the representations of mestizo, criollo, and indigenous women who lived in three different American borderlands: the island of Santa Catarina in Brazil; the Bahia de la Concepción in Chile and Monterrey in California. As women were not conceived by the illustrated travelers as an object of observation, the testimonials found are linked to the description of female work, the domestic and family sphere or sexuality, and transgressions considered as such by the male point of view. From the comparison among the three spaces, it is possible to differentiate the unequal agency possibilities of women in these spaces.
\end{abstract}

Keywords:

Tesauro: Woman, Scientific Expedition, Borderland.

Author: Eighteenth- Century, Jean-François de Galaup, Conde La Pérouse.

\section{As mulheres das fronteiras americanas na expedição científica de Jean-François de Galaup. Santa Catarina, Concepción e Monterrey (Século XVIII)}

\section{Resumo}

A viagem de circunavegação liderada por Jean-François de Galaup, Conde de la Pérouse (1785-1788) faz parte das expedições cientificas à América no século XVIII. Por meio da análise de seus diários de viagem, este artigo enfoca as representações de mestiças, criollas e indigenas que viviam em três diferentes fronteiras americanas: a Ilha de Santa Catarina no Brasil; a Bahia de la Concepción no Chile e Monterrey na Califórnia. Como as mulheres não foram concebidas pelos viajantes ilustrados como objeto de observação, os depoimentos encontrados estão vinculados à descrição do trabalho feminino, do âmbito doméstico e familiar ou da sexualidade e das transgressões tidas como tal pelo ponto de vista masculino. A partir da comparação entre os três espaços, é possivel diferenciar as possibilidades desiguais de agência das mulheres nesses espaços.

Palavras-chave:

Tesauro: Mulher, Expedição Cientifica, Fronteira. Autor: Século XVIII, Jean-François de Galaup, Conde La Pérouse. 


\section{Introducción}

Las "expediciones científicas" del siglo XVIII volcaron nuevas miradas sobre los territorios americanos. Las ambiciones de renovar los límites del conocimiento llevaron a astrónomos geógrafos, botánicos, médicos naturalistas, estudiosos ilustrados, en general, hacia los confines del planeta en largos viajes y eruditas exploraciones. Este espíritu científico no estuvo exento de aventura, pasiones, infortunios y, por supuesto, de grandes descubrimientos. Además, estuvo enmarcado en la rivalidad imperial entre las monarquías ibéricas y otras como la francesa y la inglesa. La necesidad de delimitar nítidamente las fronteras y de impedir las pretensiones expansionistas de las coronas rivales dejaron su impronta en estas empresas. De este modo, el registro de datos científicos estuvo acompañado de juicios y denuncias por parte de los extranjeros sobre el estado deplorable y las miserables condiciones de vida de los indígenas americanos dentro de los dominios hispanos y portugueses. A pesar del inherente sesgo y de los intereses políticos que permearon las observaciones de los distintos viajeros y científicos que recorrieron tierras americanas durante este siglo, sus observaciones sobre las sociedades que encontraron a su paso nos permiten tener un referente de contraste con la información producida por las autoridades coloniales, que más allá de exhibir presumidas verdades ponen de relieve lo que llamó la atención de la mirada ajena.

Este trabajo se propone analizar el modo en que Jean-François de Galaup conde de La Pérouse, oficial naval francés, representó a las mujeres americanas (indígenas, mestizas y criollas) de tres fronteras. El itinerario de viaje de este explorador ofrece la posibilidad de cotejar tres espacios cuya demografía, organización social e importancia geopolítica era disímil pero que compartían su situación de espacios limítrofes y defensivos. Primero, en la isla de Santa Catarina, territorio en pugna entre España y Portugal; después, en la Bahía de Concepción en Chile, en la llamada frontera mapuche y, finalmente, en la Alta California, frontera misional al norte de la Nueva España. A la luz del imaginario ilustrado del que abrevaba La Pérouse, el objetivo es mostrar que sus señalamientos y caracterizaciones sobre estas mujeres comparten ciertos supuestos con las opiniones de otros viajeros de la época, pero al mismo tiempo dependieron de su experiencia personal y de las condiciones específicas de cada una de las regiones. Asimismo, este trabajo se propone contrastar rescatar aquellos indicios, que permitan esbozar algunos rasgos del papel y formas de vida de las mujeres en cada una de estas regiones. Para ello iniciamos con un breve recuento de algunas de las expediciones españolas, inglesas y francesas que sentaron los precedentes del viaje y que abrieron un horizonte de comprensión en el que confluían los ideales ilustrados, el nuevo programa económico y geoestratégico y la rivalidad entre las monarquías europeas. La segunda parte se concentra en la vida de este oficial, al servicio de Luis XVI, cuya amplia experiencia militar y marítima no lo exentó de encontrar un final trágico en los confines de Oceanía. En la tercera parte, se contextualizan las tres fronteras coloniales y se rescatan las observaciones que sobre las mujeres asentó La Pérouse. 


\section{Las expediciones científicas del siglo XVIII}

En general, las expediciones científicas del siglo XVIII fueron multidisciplinarias, pero también las hubo con objetivos particulares. ${ }^{1}$ No obstante, una característica que compartieron, independientemente de la corona que las auspiciaba o del enfoque que las guiaba, fue que se trató siempre de empresas compuestas y dirigidas por varones cuyos intereses de observación no incluían a las mujeres, por lo que las menciones a ellas fueron siempre marginales. Aunque, en muchos casos, las mujeres desempeñaron diversas labores en estas empresas, su trabajo fue invisibilizado. ${ }^{2}$

Dentro de las expediciones botánicas promovidas por las autoridades hispanas se pueden destacar, en primer lugar, la Expedición botánica del Perú (17771816) que recorrió las costas de Chile, Perú y Ecuador, a cargo de los botánicos españoles Hipólito Ruiz y José Pavón cuyo objetivo apuntaba al descubrimiento de las propiedades terapéuticas de ciertas plantas, aunque no dejaron de hacer juicios sobre las mujeres al condenar el trato de los maridos hacia ellas y sus amantes. ${ }^{3}$ Una segunda es la Expedición al Reino de la Nueva Granada (1783-1816) que estuvo a cargo de Celestino Mutis y Bosio quien llegó a América como médico del virrey Pedro Messía de la Cerda, por lo que muchas de sus contribuciones fueron en el ámbito de la enseñanza y la práctica de la medicina, además de haber dejado alrededor de seis mil imágenes que se resguardan en Archivo del Real Jardín Botánico. ${ }^{4}$ En su obra, las mujeres aparecen de manera esporádica, por ejemplo, duda de que los animales peligrosos, como alacranes y culebras hicieran daño a las mujeres preñadas. También podemos destacar la de Martín Sessé en la Nueva España (1787-1803), que de acuerdo con la Real orden de Carlos III, del 20 de marzo de 1787, tenía como objetivos "promover los progresos de las Ciencias Phísicas, desterrando las dudas, y adulteraciones, que hay en la Medicina, Tintura y otras Artes útiles y aumentar el

\footnotetext{
${ }^{1}$ Para una revisión de las expediciones en este siglo ver Calatayud, María de los Ángeles. Catálogo de las expediciones y viajes científicos españoles a América y Filipinas (siglos XVIII y XIX) (Madrid: Consejo Superior de Investigaciones Científicas, Museo Nacional Ciencias Naturales, 1984). Escudero, Lola. "Viajes, ciencia e ilustración. las expediciones científicas españolas en el siglo XVIII", en Boletín de la Sociedad Geográfica Española, núm. 22, Madrid, Sociedad Geográfica Española, 2005, pp.10-25. PuigSamper, Miguel Ángel. "Las expediciones científicas españolas en el siglo XVIII”, en Canelobre, núm. 57, Alicante, Instituto Alicantino de Cultura Juan Gil-Albert, 2011, pp. 20-41. https://www.casadevelazquez. org/fileadmin/fichiers/investigacion/Ateliers/Conocer/Las_expediciones_cient \%C3\%ADficas_ espa\%C3\%B1olas_en_el_siglo_XVIII.pdf

${ }^{2}$ Tatiana Lobato, "Botánica: una ciencia femenina en Latinoamérica”, La ventana, 6, 48 (2018): 236-263.

${ }^{3}$ Hipólito Ruiz, Relación del viaje hecho a los reinos del Perú y Chile por los botánicos y dibujantes enviados por el Rey, Introducción, transcripción y notas de Raúl Rodríguez Nozal y Antonio González Bueno (Madrid: Consejo Superior de Investigaciones Científicas, 2007).

${ }^{4}$ Otra serie de discusiones historiográficas sobre Mutis se han abocado a la confrontación entre su pensamiento liberal y su oposición a los movimientos emancipadores de inicios del siglo XIX. José Amaya, Antonio. Celestino Mutis y la expedición botánica (Madrid: Debate, 1986). En cuanto a los dibujos se pueden consultar en la Biblioteca Digital AECID. Real Expedición Botánica del Nuevo Reino de Granada. Flora de la Real Expedición Botánica del Nuevo Reino de Granada (Madrid: Gobiernos de España y de Colombia entre los Institutos de Cultura Hispánica de Madrid y Bogotá, 2010). http://bibliotecadigital. aecid.es/bibliodig/es/consulta/registro.cmd?id=3148
} 
comercio". ${ }^{5}$ Otras expediciones notables fueron las de Juan de Cuéllar a las Filipinas en la Tercera Comisión Botánica española con el objetivo de contribuir con los conocimientos botánicos de plantas medicinales con fines industriales y comerciales. ${ }^{6}$ Y la Real Comisión de Guantánamo a la Isla de Cuba (1796-1802) de Baltasar Manuel Boldo quien recorrió la isla de Cuba y redactó un informe sobre su geografía producción y habitantes. Su principal objetivo era mapear la bahía de Guantánamo con fines militares, no obstante, hizo agudas observaciones botánicas y médicas.?

Todas estas empresas compartían el ideal de las contribuciones que la historia natural podía hacer al desarrollo económico de los reinos, en el que las mujeres podían contribuir al bien común "ocupándose de la moralidad y el bienestar privados, condición necesaria de la felicidad colectiva". ${ }^{8}$ El proyecto borbón intentó, durante las últimas décadas del siglo XVIII, inventariar los recursos naturales para impulsar su explotación, lo que "le permitiera incrementar y monopolizar el comercio tanto en América como en Europa". ${ }^{9}$ Se sumaba a ello, la necesidad de defender sus territorios de ultramar de las pretensiones de otras monarquías. Por ello, también se llevaron a cabo expediciones que priorizaron el carácter político para fijar las fronteras entre los dominios lusos y los hispanos. Este fue el caso de la expedición del naturalista Félix de Azara a América del Sur, entre 1781 y1801, de la cual quedó el testimonio titulado Viajes por la América meridional. ${ }^{10}$ En el mismo tono, las dos Comisiones Demarcadoras de Límites, una al mando de José Iturriaga, con la colaboración de Pehr Löfling ${ }^{11}$ y la otra comandada por Gomes Freire y Gaspar Tello, conde de Valdelirios, intentaban establecer los límites con Portugal en el Sudamérica después de la firma del tratado de Madrid. ${ }^{12}$ Los objetivos políticos y científicos con miras a impedir la penetración de los holandeses y franceses en el norte de la Amazonía y la región del Orinoco no se consiguieron pero "las repercusiones en el campo científico y técnico fueron de gran importancia". ${ }^{13} \mathrm{El}$

\footnotetext{
${ }^{5}$ José Luis Maldonado Polo, “La expedición botánica a Nueva España, 1786-1803: el Jardín Botánico y la Cátedra de Botánica", Historia Mexicana, L, 1 ( 2000): 12

${ }^{6}$ María Pilar San Pío Aladrén (coord.) La expedición de Juan de Cuéllar a Filipinas (Madrid: Consejo Superior de Investigaciones Científicas, CSIC, Real Jardín Botánico, Lunwerg, Caja Madrid, 1997). Esta obra reúne el contexto de Filipinas en el siglo XVIII, datos biográficos de Cuéllar y un análisis de las imágenes de la expedición.

${ }^{7}$ Real Comisión de Guantánamo. Cuba ilustrada. La Real Comisión de Guantánamo 1796-1802 (Madrid: Sociedad Estatal Quinto Centenario, Ministerio de Agricultura Pesca y Alimentación, Museo Naval Madrid, Real Jardín Botánico, Ministerio de Obras Públicas y Transportes, Lunwerg editores, 1991).

${ }^{8}$ Mónica Bolufer Peruga, "Las mujeres en la cultura de la Ilustración”, en Martínez, Enrique y de Pazzis, Magdalena (eds.), Ilustración, ciencia y técnica en el siglo XVIII (Valencia: Universidad de Valencia, 2008), 210.

${ }^{9}$ Graciela Zamudio Valera, "Las expediciones botánicas a América en el siglo XVIII”, Ciencias, 29 (1993).

${ }^{10}$ Félix Azara, Viajes por la América Meridional (Madrid: Espasa Calpe, 1969).

${ }^{11}$ La información recuperada por Löfling quedó plasmada en su Diario de las herborizaciones realizadas en América que quedó inédito, pero con sus informaciones Linné publicó en el año 1758 el Iter Hispanicum. Francisco Pelayo López, (ed.) Pehr Löfling y la expedición al Orinoco: 1754-1761 (Madrid: CSIC, 1990).

${ }^{12}$ Maria de Fátima Costa, "Viajes en la frontera colonial. Historias de una expedición de límites en la América Meridional (1753-1754)", Anales del Museo de América, 16 (2008): 113.

${ }^{13}$ María Matute Corona, “Cádiz y la expedición de límites al Orinoco (1754-1761): Pedro Virgili y Pehr
} 
carácter militar de estas expediciones se conjugó con los intereses científicos de la época, de modo que, a estas empresas se sumaban soldados, naturalistas, cartógrafos, astrónomos, dibujantes entre otros. Cabe señalar que las obras que legaron estos viajeros tuvieron importantes repercusiones dentro de los procesos independentistas del continente pues sus informaciones y valoraciones se utilizaron para nutrir la crítica al orden colonial. En todo caso, las menciones a las mujeres son escasas y, en el testimonio de Azara, acotadas a su participación en las actividades productivas, específicamente en las faenas del tabaco en Asunción. ${ }^{14}$

Entre las numerosas expediciones científicas, resalta la Expedición geodésica franco-española al Reino de Quito, que comenzó en 1736, la cual cuenta con una bibliografía abundante. Valga para esta introducción mencionar a sus más destacados integrantes. Por el lado francés encontramos al hidrógrafo, geómetra y astrónomo, Pierre Bouguer y al geógrafo y matemático Charles-Marie de la Condamine, cuya obra se publicó primero en español y luego en francés, mientras que un resumen de esta se leyó en la Academia de Ciencias de París el 7 de noviembre de $1745 .{ }^{15}$ Por el lado español, estuvieron Jorge Juan y Antonio de Ulloa, ${ }^{16}$ ambos matemáticos y astrónomos, quienes fueron asignados por la corona para acompañar a los académicos franceses. ${ }^{17}$ Esta expedición, propuesta por Louis Godin, bajo la aquiescencia de Felipe V, tenía el objetivo de poner fin a la polémica sobre la forma de la Tierra y medir los grados de latitud en el arco del meridiano de la tierra. Las obras publicadas por estos estudiosos incluyen controversiales opiniones sobre los habitantes americanos, las formas de gobierno y el estado general los reinos americanos, pero en ocasiones reconocieron ciertos gestos de civilidad entre las indias. A la Condamine, por ejemplo, le sorprendió "agradablemente" encontrar a las indígenas de los alrededores de Sao Paulo vestidas con camisas de lona. ${ }^{18}$ Finalmente, la Expedición Malaspina (1789-1794), fue la última de las exploraciones bajo el reinado de Carlos III. Bajo el título de Viaje político-científico alrededor del mundo, ${ }^{19}$ se dio cuenta de la primera empresa de circunnavegación española, que se proponía analizar el sistema

\footnotetext{
Löfling”, Revista Hispano Americana, 8 (2018): 13.

${ }^{14}$ Félix Azara, Diario de la navegación y reconocimiento del río Tebicuari, día 25, https://biblioteca.org.ar/ libros/131007.pdf (25 de marzo de 2021)

${ }^{15}$ Charles-Marie de La Condamine, Relation abrégée d'un voyage fait dans l'interieur de l'Amérique Méridionale. Depuis la côte de la Mer du Sud, jusqu'aux côtes du Brésil \& de la Guiane, en descendant la riviere des Amazones; lûe à l'assemblée ces, le 28. avril 1745. Par M. de La Condamine. Avec une carte du Maragnon levée par le même (París: Veuve Pissot, 1745).

${ }^{16}$ Juan Jorge. Relacion historica del viage a la America Meridional hecho de orden de S. Mag. para medir algunos grados de meridiano, 4 v, (Madrid: Antonio Marin, 1748). Ulloa, Antonio de. Noticias americanas: entretenimientos phisico-historicos sobre la América meridional, y la septentrional oriental (Madrid: Don Francisco Manuel de Mena, 1772).

${ }^{17}$ En ese informe Ulloa dio noticias devastadoras de corrupción y mal gobierno. Whitaker, Arthur. "Antonio De Ulloa." The Hispanic American Historical Review 15, 2 (1935): 155-194.

18 La Condamine 90. También descalifica la existencia de las mujeres guerreras descritas por el padre Acuña y Orellana en el siglo XVI y reconoce las duras condiciones de vida de las mujeres que siguen a sus maridos a la guerra. La Condamine 102-110.

${ }^{19}$ Alessandro Malaspina, Viaje político-cientifico alrededor del mundo por las corbetas Descubierta y Atrevida (Madrid: Imprenta de la viuda e hijos de Abienzo, 1885).
} 
comercial, la capacidad defensiva y ofensiva de los territorios, además de hacer un análisis zoológico, botánico, mineralógico, geográfico e histórico de los territorios. ${ }^{20}$ De sus ricas observaciones cabe destacar que en el "Examen político de los dominios ultramarinos de España" Malaspina apunta como un inconveniente del sistema militar: "pocas mujeres y muchos célibes" ${ }^{21}$ La expedición llegó primero al estuario del Río de la Plata, pasó por la Tierra del Fuego, avanzó al Norte hasta llegar a Alaska y cruzó el Pacífico hasta las Filipinas y Oceanía. Este viaje resulta de particular importancia porque siguió los trazos de itinerarios previos como los de James Cook y el Conde de La Pérouse y nos conduce a recuperar algunas expediciones auspiciadas por Francia e Inglaterra.

Ambas coronas respaldaron con entusiasmo diversos viajes de exploración. Por ejemplo, la circunnavegación de John Byron (1764-1766) o la del comodoro George Anson (1740-1744) en la que también había participado Byron y en la cual, a bordo de la fragata The Wager, sufrió un naufragio frente a las costas del actual Chile lo que, a su vez, desembocó en un motín y un cautiverio. El testimonio de esta aventura quedó asentado en el Relato del honorable John Byron (comodoro de la última expedición alrededor del mundo). En él aparece un pasaje que ejemplifica el tipo de relaciones que los viajeros solían establecer con las mujeres indígenas. Después de haber recibido el apoyo de un grupo de indios del Estrecho de Magallanes, los varones de la tripulación, sin vigilancia, "trataron de seducirles sus mujeres, lo que ofendió de tal manera a los indios que en poco tiempo hallaron modo de marcharse llevándose todo consigo".22

Entre los más célebres viajes ingleses se encuentran los de James Cook, (1768-1771, 1772-1775 y 1776-1780) ${ }^{23}$, cuya experiencia no sólo influyó a otros navegantes, también impulsó los esfuerzos para el reconocimiento de los océanos y las descripciones etnográficas, geográficas y botánicas. "La consagración de Cook como el mayor explorador del siglo [...] involucró también un nuevo concepto de la superioridad británica en términos geográficos y científicos. ${ }^{24}$ A lo largo de su copiosa

\footnotetext{
${ }^{20}$ Virginia González Claverán, La expedición científica de Malaspina en Nueva España: 1789-1794 (México: El Colegio de México, 1988), 21.

${ }^{21}$ Claverán XXIX. Malaspina da noticia de las mujeres de distintas regiones, pero de las patagonas reconoce su disponibilidad al diálogo e interés por usar palabras en castellano. Incluso destaca la ayuda brindada por dos de ellas en el proceso de comunicación (65-66). Preocupado por el relajamiento de la disciplina militar de su tripulación, varias de sus observaciones recalcan el "libertinaje" de ciertas mujeres, como las de Chiloé aunque no deja de señalar su belleza y laboriosidad en el trabajo textil $(80,582,579)$.

${ }^{22}$ Byron, John. Relato del honorable John Byron (comodoro de la última expedición alrededor del mundo). Que contiene una esposición de las grandes penurias sufridas por él i sus compañeros en la costa de la Patagonia desde el año 1740 hasta su arribo a Inglaterra en 1746 con una descripción de Santiago de Chile $i$ de las usanzas $i$ costumbres de sus habitantes $i$ ademas una relacion de la pérdida de la fragata Wager de la escruadra del Almirante Anson (Santiago de Chile: Imprenta Cervantes, 1901), p. 33. [Traducido de la primera edición inglesa de 1768 por José Valenzuela].

${ }^{23}$ James Cook, The Three Voyages Of Captain James Cook Round The World, 7 v. (London: A. \& R. Spottiswoode, 1821).

${ }^{24}$ Paredes, Rogelio. "Guerra en los libros. La competencia colonial del siglo XVIII entre Gran Bretaña y Francia en los libros del Museo Etnográfico de Buenos Aires (1690-1800)”, Avances del Cesor, VIII, 8 (2011): 129-154.
} 
obra, las mujeres aparecen en descripciones que atañen a sus rasgos físicos, vestimenta, su interés por obtener los productos novedosos que llevaban consigo los viajeros. La gran trascendencia de los viajes de Cook se debió, entre otras cosas, al gran interés que suscitaron las noticias de aquellos mundos ignotos y a las diversas ediciones que se hicieron de sus informes, tanto las auspiciadas por el almirantazgo británico como la serie de relatos "clandestinos" que diversos marineros filtraron para conseguir fama o dinero. ${ }^{25}$

Entre los más notables viajes de exploración auspiciados por los franceses están la expedición de Louis Antoine de Bougainville (1766-1769) ${ }^{26}$ y la del conde La Pérouse (1785-1788), cuyo trágico final remite al del tercer viaje de Cook. ${ }^{27}$ Bougainville, fue un militar y marino francés en cuyo viaje se apoderó de las Islas Malvinas; sin embargo, después de varias negociaciones tuvo que devolverlas, en 1766, a la corona española. A partir de entonces inició un viaje hacia el estrecho de Magallanes en el que lo acompañaron, a bordo de la fragata Boudeuse y Étoile, trescientos hombres, entre los que iban científicos, cartógrafos, un astrónomo y el naturalista Philibert Commerson, botánico de Luis XVI, a quien acompañaba un criado de nombre Baret. Posteriormente se descubrió que se trataba de Jeanne Baret, una botánica que se convirtió así en la primera mujer en dar la vuelta al mundo. A pesar de que el auto de 1689 prohibía a las mujeres embarcar en naves de la Marine Royale, y gracias a la ayuda de Commerson, Baret logró pasar desapercibida en el viaje hasta que un grupo de hombres tahitianos la descubrieron e intentaron robarla. ${ }^{28}$ Las contribuciones de las mujeres a la botánica se invisibilizaron en tanto sus labores de recolección, clasificación, ilustraciones fueron incluidas en los reportes, pero no se les dio el crédito. De manera concomitante, durante la Ilustración, se forjó una imagen alegórica que asociaba a las mujeres cultas con flores cultivadas. ${ }^{29}$ De este modo, la construcción del modelo de la feminidad reproducía la tensión entre naturaleza y cultura, entre razón y sentimiento y asociaba ciertas cualidades naturales a las mujeres.

En este breve recuento de algunos de los viajes de exploración promovidos por las distintas monarquías europeas es posible distinguir que todos ellos comulgaban con un antropocentrismo ilustrado preocupado por el conocimiento para la dominación y explotación de la naturaleza. En ese contexto, en Europa es notable la presencia de mujeres en ámbitos culturales novedosos como los salones, las

\footnotetext{
${ }^{25}$ Marta Torres Santo Domingo, "Los viajes del capitán Cook en el siglo XVIII: una revisión bibliográfica", en Biblio3W, Revista Bibliográfica de Geografia y Ciencias Sociales, VIII, 441 (2003): 2-3.

${ }^{26}$ Louis Antoine de Bougainville, Viaje alrededor del mundo por la fragata del Rey La "Boudeuse" y la fusta la "Estrella" en 1767, 1768 y 1769. 2 v., traducido del francés por Josefina Gallego de Dantín (Madrid: Editorial Calpe, 1921).

${ }^{27}$ Para una síntesis de los viajes de exploración franceses e ingleses ver Brosse, Jacques, Les tours du monde des explorateurs. Les grands voyages maritimes, 1764-1843 (París: Bordas, 1983).

${ }^{28}$ Esta versión es cuestionada por Glynis Ridley a partir de los diarios de otros miembros de la tripulación quienes afirmaron que Baret fue brutalmente expuesta y violada por sus compañeros de viaje. Ridley, Glynis. The Discovery of Jeanne Baret: a story of science, the high seas, and the first woman to circumnavigate the world (Nueva York: Harper Collins, 2011).

${ }^{29}$ Sam George, "The cultivation of the female mind: enlightened growth, luxuriant decay and botanical analogy in eighteenth-century texts", History of European Ideas, 31, 2 (2005): 209-223.
} 
sociedades de lecturas, o demostraciones de científicas además de que se insertaban a las discusiones políticas en espacios de sociabilidad mixtos. Pero al mismo tiempo, la Ilustración forjó una ideología de la domesticidad que separaba la esfera femenina de la masculina, la cual caracterizó la concepción y práctica de la esfera pública. ${ }^{30}$

Por otra parte, cada una de estas empresas de exploración combinó el moderno espíritu ilustrado, la propaganda política de las monarquías y programas económicos o "remedios para el imperio". ${ }^{31}$ De este modo, la producción de conocimientos científicos no fue desinteresada y estuvo vinculada a proyectos imperiales. "El tránsito hacia la modernidad convierte la ciencia en una actividad altamente prestigiada, qué progresivamente comienza a introducirse en los discursos sobre el poder, el buen gobernante y la nación." ${ }^{32}$ Esta conjugación implicó una divergencia en las apreciaciones sobre las tierras americanas y sus pobladores. Por ejemplo, ahí donde Amédée François Frezier -ingeniero militar francés que, por órdenes de Luis XIV, recorrió las costas de Perú y Chile a inicios del siglo XVIII- se burlaba de las procesiones y los flagelos religiosos, a los que llamaba "devoción mal entendida" y aludía a la prohibición que Francia hizo de estos castigos de la carne desde $1601 .{ }^{33}$ El contraste es notable si se compara con los testimonios del español Antonio de Ulloa, en su obra Relación histórica del viaje a la América Meridional, subrayaban la fastuosidad de las iglesias y las ceremonias, la belleza y exotismo de las mujeres y el esplendor de la nobleza. ${ }^{34}$ Sin embargo, un rasgo compartido por las obras de viajeros españoles y aquellos ajenos a la monarquía hispánica, es el generalizado desprecio a los habitantes del Nuevo Mundo.

Las expediciones que se llevaron a cabo durante el siglo XVIII dejaron un vasto cúmulo de obras, documentos y correspondencia que, además de las representaciones geográficas y cartográficas, observaciones astronómicas y detalles etnográficos, incluyeron catálogos, ilustraciones $\mathrm{y}$ hasta informes secretos. $^{35}$

\footnotetext{
${ }^{30}$ Bolufer 212.

${ }^{31}$ Mauricio Nieto Olarte, Remedios para el imperio. Historia natural y apropiación del Nuevo Mundo (Bogotá: Instituto Colombiano de Antropología e Historia, 2000).

${ }^{32}$ Raúl Hernández Ascencio, El matemático impaciente. La Condamine, las pirámides de Quito y la ciencia ilustrada (1740 -1751) (Lima: Instituto de Estudios Peruanos, Instituto Francés de Estudios Andinos, 2008 ), 15.

${ }_{33}$ Amédée François Frezier, Relation du voyage de la mer du Sud aux cotes du Chili, du Perou, et du Bresil, fait pendant les années 1712, 1713 \& 1714, T. 1 (Amsterdam: Pierre Humbert, 1717), 219. Todas las traducciones del francés son mías. Frezier participaba de una misión secreta en la que camuflados como comerciantes realizaron espionaje militar. Los resultados del viaje se publicaron en 1716 bajo el nombre de Relation du voyage de la Mer du Sud aux cotes du Chily et du Perou. En general las informaciones cubrían rutas marinas, datos sobre instalaciones militares, prácticas mineras, algunos apuntes sobre la forma de gobierno y noticias sobre los llamados indios de Chile. Barnés, Mónica. "Frezier, Amédée François (16821773)", en Pillsbury, Joanne (ed.), Fuentes documentales para los estudios andinos 1530-1900, v. II (Lima: Center for Advanced Study in the Visual Arts (CASVA), National Gallery of Art and Pontificia Universidad Católica del Perú, 2016), 1132.

${ }^{34}$ David Brading, Orbe indiano. De la monarquía católica a la República criolla, 14921867 (México: Fondo de Cultura Económica, 2003), 459.

${ }^{35}$ Para una síntesis de los productos y obras más representativas de estos viajes véase Rodríguez Nozal Raúl. "La obra impresa del programa expedicionario español en América", en Baratas Díaz, Luis Alfredo (coord.), Memorias de la Real Sociedad Española de Historia Natural, t. 3 (Madrid: Real Sociedad Española de Historia Natural, 2004), 34-72.
} 
En estas narraciones se alternan las descripciones y la profusión de datos con la reiteración de prejuicios, arquetipos y, en muchos casos, relatos ficcionales. Todo ello hace de estas obras ricas fuentes para la historia, pero representan también un reto metodológico para su crítica y análisis. ${ }^{36}$ Por otro lado, la profusión de estilos, la retórica propia de cada uno de los autores y las estructuras formales hacen que estos textos puedan ser analizados como obras literarias e incluso considerarse como un género. ${ }^{37}$ Pero la íntima relación de las narraciones de viaje con sus autores nos provee de un amplio horizonte de referentes para situar a las informaciones asentadas en ellas dentro del contexto de su enunciación. De este modo, uno de los intereses de este trabajo es analizar, a la luz del ideario ilustrado compartido por estos expedicionarios, los testimonios que el conde de La Pérouse asentó en sus informes sobre las mujeres de tres distintas fronteras americanas.

\section{Jean-François de Galaup, conde de La Pérouse}

Jean-François de Galaup conde de La Pérouse (1741-1788) fue un oficial de la marina francesa, perteneciente a un antiguo linaje noble de la región de Albi, donde realizó estudios en el Colegio jesuita local. Ingresó a la marina a temprana edad donde adquirió experiencia militar y de navegación, primero en la costa norteamericana, en el marco de la Guerra de los Siete años (1756-1763) y después durante la Independencia de las Trece colonias (1778-1783). Hizo campaña en el mar Caribe, primero en Haití (1771) y luego en la toma de Granada contra la flota de Byron (1779). También viajó por el Océano Índico (1773-1777). Su participación en la expedición a la Bahía de Hudson le retribuyó en ascensos militares y en el reconocimiento que le valió postularse para llevar a cabo una expedición alrededor del mundo. ${ }^{38}$

En 1783, el rey Luis XVI le comisionó la misión de descubrir nuevas rutas marítimas en el Océano Pacífico e iniciar un viaje alrededor del mundo. El conocimiento de la costa norte del Pacífico americano, desde las Californias hasta el Polo Norte, había sido un enigma hasta principios del siglo XVIII. Hasta entonces, las exploraciones de la región habían corrido a cargo de rusos como Vitus Bering y Chirikov (1726-1742) mientras que los españoles, desde mediados del siglo, conscientes de las amenazas extranjeras, trabajaban para aumentar su capacidad defensiva y apoyar la expansión hacia el Norte. ${ }^{39}$ Por su parte, entre ingleses y franceses, principalmente, persistían las conjeturas sobre la existencia de un vasto Mar Occidental que comunicara al Pacífico con el Atlántico. ${ }^{40}$

\footnotetext{
${ }^{36}$ Fredy Montoya, "Controversias epistemológicas en torno a los viajeros del nuevo Reino de Granada, siglo XVIII”, Telar, s/v, 11-12, Tucumán, Instituto Interdisciplinario de Estudios Latinoamericanos, 2014, $196-214$.

${ }^{37}$ Alburquerque García, Luis. "Los 'libros de viaje' como género literario”», en Lucena, Manuel y Pimentel, Juan (eds.), Diez estudios sobre literatura de viajes (Madrid: CSIC, 2006), pp. 67-87.

${ }^{38}$ Omar Ortiz- $\neg$ Troncoso, "La Pérousse explorador Del Pacifico", en Revista de Marina, núm. 787, Viña del Mar, Armada de Chile,1988, 2-4.

${ }^{39}$ Hilton, Sylvia. "El límite noroccidental del imperio hispanoamericano 1513-1784” en Abbad y Lasierra, Íñigo. Descripción de las costas de California (Madrid: Consejo Superior de Investigaciones Científicas, Instituto "Gonzalo Fernández de Oviedo", 1981), 27.

${ }^{40}$ Las Cartes des Nouvelles découvertes au Nord de la Mer du Sud, elaborado por Nicolás Delise y Philippe
} 
Si bien, las expediciones británicas de James Cook tuvieron un inmenso impacto en los círculos científicos europeos, las lecturas náuticas que Pérouse hizo de la costa, desde Alaska hasta Monterrey en California, concluyeron que no existía dicho Mar Occidental. La Pérouse reconoció ampliamente los conocimientos de Cook que a su parecer "merecían la justa admiración del mundo entero", ${ }^{41}$ y trazó buena parte de su ruta por Oceanía, Nueva Caledonia y Hawái siguiendo sus informaciones. Pero, como Bougainville, La Pérouse participaba del interés de la monarquía francesa por establecer nuevas bases en el Pacífico para consolidar su poder económico y político.

La Pérouse zarpó desde el puerto de Brest, el 1 de agosto de 1785, al mando de dos fragatas -el Astrolabe y el Boussole - con alrededor de cuatrocientos hombres, entre los que había un médico, un astrónomo, un meteorólogo, hidrógrafos, botánicos, naturalistas y diseñadores. Tres años después la flota se perdió y no se recibieron más noticias de ellos. Durante muchos años, el destino del conde de La Pérouse permaneció como una incógnita. En 1791, las autoridades francesas enviaron un grupo de búsqueda al mando de Joseph Antoine Bruni d'Entrecasteaux, pero no tuvo éxito. No obstante, en enero de 1788, en Francia se recibió la noticia de la existencia de los diarios de viaje La Pérouse, con lo que se pudo completar un mapa preliminar del viaje. En 1797, LouisAntoine Milet-Mureau, encargado por la Asamblea Nacional, editó Voyage de La Pérouse autour du Monde, basado en las informaciones enviadas por del conde desde Kamchatka y Botany Bay. ${ }^{42}$ Ala par se editó el Atlas du voyage de La Pérouse. ${ }^{43}$ También se conservan obras publicadas de forma póstuma, como la Relation abrégée du voyage de La Pérouse, pendant les années 1785, 1786, 1787 et 1788, publicada en $1799 .{ }^{44}$

Después de pasar por las islas de Madeira, Tenerife y la costa de Brasil, la expedición llegó al Cabo de Hornos a fines de enero 1786. Entraron a la bahía de Concepción en Chile en febrero y fondearon en Talcahuano, donde permanecieron hasta el 15 de marzo. La Perouse diseñó un plano de la bahía y emitió un informe sobre la sociedad chilena, que remitió al gobierno francés. A inicios de abril llegaron a Isla de Pascua, en mayo, a las Islas Sandwich (Hawái) y en junio a las costas de Alaska. A partir de este punto navegó con rumbo al sur haciendo levantamientos hidrográficos hasta las costas de California y el puerto de Monterrey. Desde ahí planificaron la ruta hacia Kamchatka y después de atravesar todo el Pacífico entraron en Macao, China, el 3 de enero de 1787. Luego de explorar parte de Japón, a finales de febrero de ese año, arribaron a la bahía de Manila. El 7 de septiembre, hicieron una escala en la península de Kamtchatka. De ahí siguieron al Pacífico central,

\footnotetext{
Buache en 1752 mostraban una síntesis de los conocimientos geográficos que se tenían sobre el Pacífico septentrional hasta ese momento. Pinzón Rios, Guadalupe, "El Pacifico novohispano a partir del Mapa de la América Septentrional de 1754”, en Estudios Jalisciences, 107, Zapopan, El Colegio de Jalisco, 2017, 18-31.

${ }^{41}$ Jean-François de Galaup La Pérouse, [redactado por Milet-Mureau, Louis Antoine] Voyage de La Pérouse autour du Monde, t. II (París: Imprimerie de la République, 1797), 6.

${ }^{42}$ De Galaup 6.

${ }^{43}$ Jean-François de Galaup La Pérouse, Atlas du voyage de La Pérouse (París: Imprimerie de la République, 1797).

44 Jean-François de Galaup La Pérouse, Relation abrégée du voyage de La Pérouse pendant les années 1785, 1786, 1787 et 1788 (Leipzig: s.e., 1799).
} 
pasaron por las islas Samoa en diciembre y, el 26 de enero de 1788, arribaron a Botany Bay, Australia. A mediados de marzo, después de dos años y medio de viaje, zarparon en dirección noreste, pero por las condiciones provocadas por un ciclón, las fragatas se estallaron cerca de las islas Salomón a mediados de junio de $1788 .{ }^{45}$

Desde entonces el paradero de La Pérouse y su tripulación permaneció como un enigma hasta que, durante la expedición de Dumont d'Urville, en 1828, se encontraron e identificaron algunos objetos del naufragio, entre ellos algunas medallas de La Pérouse, frente a Vanikoro, una de las islas de Salomón. Fue, sin embargo, hasta 1964 que un buzo de nacionalidad neozelandesa encontró los restos del Astrolabe y el Boussole.

A partir del bicentenario del inicio del viaje de La Pérouse, se multiplicaron los estudios, las exposiciones y coloquios al respecto. Si bien existe una buena cantidad de obras dedicadas a la biografía, ${ }^{46}$ al itinerario de viaje, a los preparativos, a las contribuciones navales, geográficas y de historia natural, a las influencias de viajeros como Cook y Bouganville, ${ }^{47} \mathrm{y}$ al trágico final de la expedición, son menos aquellos análisis que se han centrado en las valoraciones que hizo de la población que encontraba a su paso. ${ }^{48}$ No obstante, a lo largo de su obra es claro el interés y las preocupaciones que el contacto con las distintas poblaciones americanas y asiáticas le despertaron.

Un hombre de luces, que en sus escritos dejó constancia de su incesante curiosidad y una notable lucidez en sus juicios, asentó en sus diarios e informes críticas relativamente severas sobre la colonización europea, pero también sobre los sujetos colonizados, su carácter y las consecuencias que la dominación sobre ellos había traído. A pesar de compartir el ideal de llevar la civilización a los pueblos "salvajes", La Pérouse no dejó de sopesar las ventajas y desventajas de ese proyecto. Al inicio del segundo tomo de Voyage de La Pérouse autour du Monde se trasluce su inquietud por las consecuencias de la intervención sobre esas tierras y se pregunta: "Los beneficios de una nueva planta harinosa, de un nuevo fruto e incluso de la introducción de animales domésticos, ¿se pueden comparar con la suma de males que deben resultar para estos pueblos de la introducción de costumbres y modales europeos?" 49 Por otra parte, su experiencia con los distintos pueblos lo llevó a renunciar a ideas generalizadoras y sobre todo a criticar la idea de que las personas en "estado de naturaleza son buenos". ${ }^{50}$ En contra del mito del buen salvaje, difundido por Rosseau,

\footnotetext{
${ }^{45}$ Ortiz-Troncoso 8-15.

${ }^{46}$ John Dunmore, La Pérouse. Explorateur du Pacifique (París: Payot, 1986).

${ }^{47}$ Catherine Gaziello, L'expédition de Lapérouse (1785-1788), réplique française aux voyages de Cook (París: La Documentation française, 1983).

${ }^{48}$ François Bellec, La Genereuse et Tragique Expedition Laperouse (Rennes: Ouest- France Université, 1985).

${ }^{49}$ La Pérouse, 6.

${ }^{50}$ Danielle Fauquel, "Il y a deux cents ans: l'expédition Lapérouse”, Revue d'histoire des sciences, t. 38, 2 (1985) : 149-160.
} 
Pérouse recuperó varios actos de crueldad y mostró la dureza de sus encuentros con los pueblos alrededor del mundo. En este contexto, las observaciones que La Pérouse hace sobre las mujeres son marginales y suelen estar relacionadas con las actividades que desempeñan, algunas características físicas y ciertos rasgos morales.

\section{La isla de Santa Catarina, Brasil: las mujeres en resguardo}

Esta isla, situada entre Río de Janeiro y el Río de la Plata, fue, desde el siglo XVI, un puerto privilegiado para los viajes entre Europa y América del Sur. ${ }^{51}$ Por su ubicación limítrofe, su densidad demográfica y la escasa presencia de autoridades portuguesas, Santa Catarina era un lugar bastante frecuentado por barcos de diversas nacionalidades y solía ser blanco de ataques ante los cuales los pobladores se refugiaban en las montañas. Ante esta situación, a mediados del siglo XVIII, la monarquía portuguesa intentó fortificar la isla para consolidar sus dominios en aquel espacio marítimo y continental.

Creada en 1726, la aldea de Desterro se consolidó veinte años después como un asentamiento importante cuya población estuvo compuesta por migrantes provenientes de las Azores y Madeira que eran "hombres y mujeres, legalmente libres, blancos y cristianos; en su mayoría personas pobres, agricultores mecánicos y militares entre otros". ${ }^{52}$ A pesar de los intentos lusitanos de defender la isla, en 1776, se llevó a cabo una operación militar comandada por Pedro de Cevallos, el primer virrey del recién creado virreinato del Río de la Plata. Esta invasión inauguró un período de gobierno español, que duró hasta 1778 cuando se restituyó la isla a los portugueses. ${ }^{53}$

De acuerdo con las noticias que tomó del relato de Frezier, La Pérouse afirma en sus informes que "esta isla sirvió, hasta 1771 , como refugio para los vagabundos que huyeron allí desde diferentes partes de Brasil; ellos no eran súbditos de Portugal más que de nombre, no reconocían autoridad alguna." ${ }^{54}$ Esta descripción resalta la ambigüedad de los espacios fronterizos americanos que por largos lapsos permanecían al margen de la política imperial y abrían amplios umbrales de negociación y transigencia de las normas. Los esfuerzos de Portugal por fortificar y poblar la isla respondían a un modelo geopolítico en el que la defensa de las fronteras resultaba crucial frente a las ambiciones de las demás monarquías.

La Pérouse arribó a la isla de Santa Catarina el 6 de noviembre de 1785. La relación que entabló con el gobernador de la capitanía don Francisco de Baros, quien hablaba muy bien el francés, fue amistosa. Conversó con él temas geopolíticos como

\footnotetext{
${ }_{51}$ Jeferson Dos Santos Mendes, "Para defender é preciso fortificar: as defesas da Ilha de Santa Catarina durante o século XVIII”, Fronteiras Revista de História, 21, 36 (2018): 200-218.

${ }^{52}$ Augusto Da Silva, “Os 'Povoadores' da ilha de Santa Catarina: Hierarquia social, trabalho livre e conflitos (1748-1800)", Revista Territórios \& Fronteiras, 8, 2 (2015): 330.

${ }^{53}$ Augusto Da silva, A Ilha de Santa Catarina e sua Terra Firme. Estudo sobre o governo de uma capitania subalterna (1738-1807). (Tesis de postgrado, Universidad de São Paulo, 2007) 17-18.

${ }^{54}$ La Pérouse 33.
} 
el conflicto con los ingleses por la isla de la Trinidad, y contó con su apoyo para abastecer a la tripulación. Sus primeras observaciones giraron en torno a la economía de la isla. En términos generales, Pérouse consideró que se trataba de tierras fértiles, pero advertía que su población era pobre.

Además de la producción de cítricos, destacó la cacería de ballena como una actividad económica importante, aunque acaparada por la Corona. Apuntó la ausencia de productos manufacturados y la imposibilidad de explotar la caña de azúcar a pesar de tener el clima idóneo. Ante dicho panorama preveía que, sin estímulos del gobierno al comercio, la tierra languidecería. ${ }^{55}$ En cuanto a las costas, llamó la atención sobre las facilidades para la navegación, pero, al igual que el comodoro Anson en 1739, insistía en la debilidad del sistema de defensa.

La única mención a las mujeres de esta isla aparece cuándo La Pérouse destaca la hospitalidad de sus pobladores a quienes describe como de "carácter dulce y modales amables, educados, serviciales, pero supersticiosos y celosos de sus esposas, que nunca aparecen en público." ${ }^{56}$ De esta escueta mención se desprenden varios elementos a tomar en cuenta. Por un lado, es necesario apuntar que La Pérouse no especifica a qué grupo de población se refiere cuando describe el carácter de los pobladores. Sin embargo, si atendemos al proceso de poblamiento incentivado por las autoridades portuguesas, aunado a la tradición de habitación de distintas clases de renegados, es posible asumir que se trata de una sociedad heterogénea en la que convivían indios, esclavos negros, europeos fugitivos y portugueses. ${ }^{57}$

Por otra parte, si tomamos en cuenta que la isla era un espacio fortificado, que había sufrido, para entonces, la invasión española y diversos ataques de embarcaciones extranjeras podemos entender la reserva de las mujeres a aparecer en el espacio público como una medida precautoria ante la amenaza de las huestes de varones que solían desembarcar en la isla. Cuando en abril de 1712, Amédée François Frezier visitó esta isla, hubo una suerte de alarma entre los habitantes mientras los franceses buscaban un abrevadero de agua dulce. Para evitar que pusieran pie en las viviendas y habiendo sido reconocidos como franceses, el gobernador o capitán de la isla envió a tres hombres en una piragua a solicitarles que no desembarcaran y ofreció a cambio víveres. Para entonces, "las mujeres asustadas ya habían huido a las montañas". ${ }^{58}$

A pesar de que se trata de dos menciones aisladas y escuetas, no deja de llamar la atención que ambos viajeros, con una distancia de más de medio siglo, hayan observado la misma práctica de resguardar y ocultar a las mujeres ante la presencia extranjera, específicamente francesa. El reiterado temor de las mujeres a permanecer en los espacios habitualmente atacados responde a un modelo de lo que significaba ser

\footnotetext{
55 La Pérouse 33-35.

${ }^{56}$ La Pérouse 39.

${ }^{57}$ Óscar Rico Boledón, La ocupación española de Santa Catarina (1777-1778). Una isla brasileña para Carlos III, (Tesis de doctorado, Universidad de Salamanca, 2013) 154.

${ }^{58}$ Frezier 33.
} 
mujer en espacios fronterizos. Si bien en muchos de ellos, el cautiverio de mujeres se configuró como el signo que mostraba la derrota, haciendo de la posesión del cuerpo femenino un signo del triunfo, ésta no fue la única práctica que proyectaba a las mujeres como botín de guerra. ${ }^{59}$ Marcela Tamagnini considera que las representaciones organizan la experiencia social y son constitutivas de ciertas prácticas. "Construir imágenes simbólicas es una de las prácticas involucradas en experiencias sociales que se hace extensiva tanto a las situaciones de la vida cotidiana como aquellas institucionalizadas." ${ }^{\prime 60}$ En este sentido, los abusos sobre el cuerpo de las mujeres en espacios de conflicto y guerra se condensaron en un imaginario que remitía a la vulnerabilidad de las mujeres y a la necesidad de protegerlas, pero también a las capacidades que desplegaron para sobrevivir en espacios sujetos al despojo, al castigo y la precariedad.

\section{La Bahía de Concepción, Chile: las mujeres se muestran y complacen}

La ciudad de Concepción, fundada en 1550, se convirtió en un enclave estratégico para la ocupación territorial del Reino de Chile y para la comunicación marítima con el Perú. La densidad de población indígena en la región representaba un incentivo para la empresa colonizadora; sin embargo, la interacción bélica con los mapuches provocó que el asentamiento fuera destruido en tres ocasiones a lo largo de sus primeros diez años de vida. Frente a la constante amenaza indígena, las autoridades dispusieron la creación de numerosas fortificaciones militares ${ }^{61} \mathrm{y}$, después del levantamiento de 1598, se creó el Real Situado que permitió financiar un contingente militar, profesional y estable, encargado de defender la línea fronteriza del río Bío-Bío. Este límite se consagraría como una de las fronteras más paradigmáticas de la expansión hispana que, para finales del siglo XVIII, se inscribía en el proyecto de articulación territorial de los borbones que destacaba por su importancia geoestratégica y su potencialidad económica. ${ }^{62}$ Caracterizada tradicionalmente como una frontera de guerra, las relaciones hispano-mapuches fluctuaron entre ciclos de enfrentamiento bélico y procesos de pacificación a través de instituciones como el comercio, las misiones y los parlamentos. La intensa circulación (incluida la movilidad forzada) dio lugar a constantes procesos de adaptación etnificación y etnogénesis. ${ }^{63}$

La Pérouse inicia la descripción de esta bahía, a la que llegó el 24 de febrero de 1786, afirmando que por, su mar tranquilo y sus escasas corrientes, era una de las más cómodas que podían encontrarse en el mundo. A su llegada, Talcahuano era el

\footnotetext{
${ }^{59}$ Yessica González, "Indias blancas tierra adentro. El cautiverio femenino en la Frontera de la Araucanía, siglos XVIII y XIX”, en Anuario Colombiano de Historia Social y de la Cultura, 43, 2 (2016): 190.

${ }^{60}$ Marcela Tamagnini y Graciana Pérez Zavala, "Mujeres de frontera: entre el cautiverio y el estigma" en IV Congreso Chileno de Antropología, Santiago de Chile, Colegio de Antropólogos de Chile A. G, 2001, https://www.aacademica.org/iv.congreso.chileno.de.antropologia/102

${ }^{61}$ Antonio Vásquez de Espinoza, Descripción de Reino de Chile (Santiago: Editorial Blas Cañas, 1986), 56-59.

${ }^{62}$ Natalia Gándara, "Representaciones de un territorio. La frontera mapuche en los proyectos ilustrados del reino de Chile en la segunda mitad del siglo XVIII", Historia Crítica, 59 (2016): 16.

${ }^{63}$ Guillaume Boccara, "El poder creador: tipos de poder y estrategias de sujeción en la frontera sur de Chile en la época colonial”, Anuario De Estudios Americanos 56, 1 (1999): 68.
} 
único poblado español en la bahía, pues después del terremoto de 1751 , la ciudad de Concepción - "que fue devorada por el mar"- había sido trasladada y refundada, en 1763, a un cuarto de legua del río Bío-Bío y a tres del asentamiento original. ${ }^{64} \mathrm{La}$ nueva ciudad tenía diez mil habitantes y el obispado nominalmente abarcaba hasta el estrecho de Magallanes, pero el viajero francés advirtió que "todo el país al sur de dicho río pertenece a los indios". ${ }^{65}$ La Pérouse insistía en que, salvo Chiloé y Valdivia, ninguno de estos pueblos eran súbditos del Rey de España, por lo que destacaban las funciones del comandante que dirigía tanto a las milicias como a los cuerpos regulares. De acuerdo con los objetivos que movían a este tipo de expediciones, los apuntes de La Pérouse se centraron en aspecto económicos, sobre el gobierno y las autoridades de esta región e introdujeron una crítica sobre la ausencia de jueces y la impartición de justicia por un individuo cuya autoridad se impone sobre el resto.

Como en el caso de Santa Catrina, también concede un breve espacio para describir la fertilidad de la tierra. Añade a ello las excelentes condiciones para la ganadería y la longevidad de sus habitantes, salvo por la presencia de una enfermedad que no se atreve a nombrar. A pesar de tantas ventajas -dice Pérouse"esta colonia está lejos de haber logrado los avances qué cabría esperar", pues el régimen prohibitivo frustraba los avances e impedía la circulación de sus producciones que, "si estuvieran al máximo, abastecerían a la mitad de Europa; cuyas lanas bastarían para las manufacturas de Francia e Inglaterra”. La crítica a la política comercial española y al atraso de la provincia se acompaña de una caracterización de los pobladores como gente acostumbrada a no trabajar y a "no desear con suficiente fuerza para vencer la inercia". Suma a ello la incomunicación en la que permanecen, por lo que "no conocen nuestras artes ni nuestros lujos", así como la poca disposición para aprender un oficio. ${ }^{66}$ Sobre los indios de Chile sólo remarca el profundo cambio que la introducción de dos animales domésticos, (el caballo y la vaca) provocó en ellos, al grado que "ya no comen los mismos frutos, apenas siguen sus viejas costumbres y tienen un parecido mucho más marcado con los tártaros o con los habitantes de las orillas del Mar Rojo que con sus antepasados". ${ }^{67}$

El interés del conde por los pobladores de las distintas regiones visitadas seguía las directrices de los intereses monárquicos y estaba inscrito en una serie de valores que la Ilustración empuñaba como estandartes. En consonancia, condenó ciertos rasgos del carácter de los pobladores de Concepción, tales como la credulidad y superstición, pero también las grandes libertades que las muchachas y los hombres gozaban en los conventos, "cuyo descaro los convertía en los peores súbditos en América". Los juicios de La Pérouse sobre la población de la bahía de la Concepción distinguieron entre "los verdaderos españoles" que estimaba educados y serviciales y aquella población "mezclada" a la que concebía como una raza

\footnotetext{
${ }^{64}$ La Pérouse 59.

${ }^{65}$ La Pérouse 60.

${ }^{66}$ La Pérouse 61.

${ }^{67}$ La Pérouse 67.
} 
degenerada, "muy ladrona" y cuyas mujeres "son extremadamente complacientes" ${ }^{68}$ Pero este carácter adjudicado negativamente a las mujeres mestizas, contrasta con la caracterización que hace las damas principales, a quienes describió como llenas de gracia, "generalmente bonitas y tan amables que ciertamente no hay ciudad marítima en Europa donde los marineros extranjeros sean recibidos con tanto cariño y simpatía." 69

A propósito de las mercaderías existentes, el viajero introdujo una nota sobre la vestimenta de las mujeres que constaba de una falda plisada, parecida a los "tejidos de oro o plata que alguna vez se fabricaron en Lyon". Es factible pensar que por la calidad o complejidad de su confección le hayan llamado la atención precisamente cuando desestimaba la circulación de mercancías y la capacidad manufacturera de ese país. Más adelante, La Pérouse dedica una buena parte a la descripción de los vestidos que las "damas principales" portaban durante un baile al que fueron convidados. Llamaron su atención varios elementos: "una falda plisada que deja la mitad de la pierna descubierta y que se ciñe debajo de la cintura, [...] medias a rayas rojas, azules y blancas; zapatos tan pequeños que los dedos están doblados de modo que el pie parece casi redondo". ${ }^{70}$ De la forma en la que llevaban el cabello destaca las trenzas que caían sobre sus hombros, y el uso de corsés dorados o plateados y dos mantillas, una de muselina y la otra de lana. Una imagen que ilustra esta vestimenta se encuentra en el Atlas du voyage de La Pérouse. (Imagen 1).

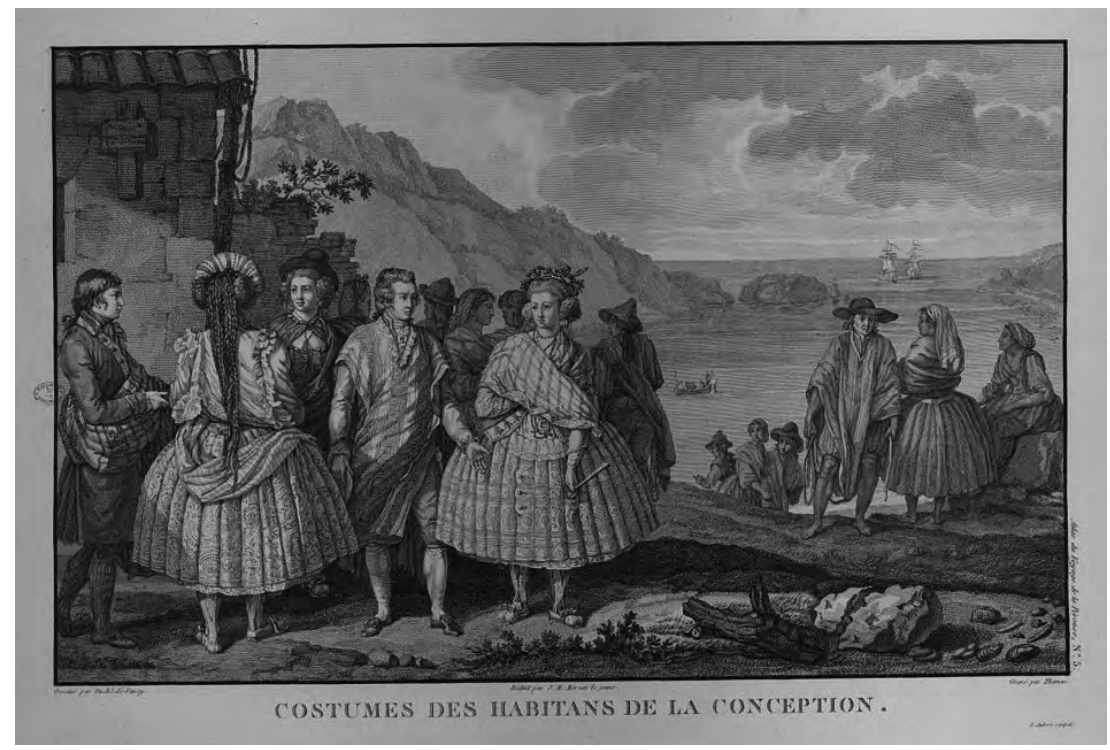

Imagen 1. Habitantes de la isla de la Concepción.

Fuente: Atlas du voyage de La Pérouse (Milet de Mureau, 1797), f. 8

\footnotetext{
${ }^{68}$ La Pérouse 64.

69 La Pérouse 66.

${ }^{70}$ La Pérouse 65.
} 
El impacto que las mujeres de Chile causaron a La Pérouse se deja ver de nueva cuenta cuando narra la última fiesta general que ellos ofrecieron antes de su partida y a la que "invitaron a todas las damas de la Concepción". ${ }^{71}$ A aquella cena frente al mar, asistió un centenar y medio de hombres y mujeres que viajaron las tres leguas desde la ciudad. Al otro día se llevó a cabo una cena y baile para la tripulación a la que también asistieron "todas las damas, vestidas con sus mejores ropas", aunque no especifica si se trataba de las damas principales o de las mujeres del pueblo, aunque parece más probable que se tratara de las últimas. Sobre estas mujeres encontramos un comentario en el que las que describe "casi tan complacientes como las de Haití". ${ }^{2}$ Este rasgo se encuentra asociado a la abundancia de vino, por lo que, según su apreciación, "cada casa del pueblo de Talcaguana es un cabaret". ${ }^{73}$

La vestimenta de las mujeres chilenas y su carácter hospitalario no solo llamaron la atención de La Pérouse. Unos años después, los artistas de la expedición de Malaspina (1789-1794) dejaron doce representaciones sobre ellas en las que, del mismo modo que Pérouse, destacan la extravagancia del vestido y "la ridiculez" de apretar los pies en pequeñas zapatillas, así como las pantorrillas y los pies descubiertos. ${ }^{74}$ Los expedicionarios científicos, Byron y Frezier ${ }^{75}$ también asentaron los gestos de amabilidad de las mujeres y su carácter jovial que rayaba en libertinaje. Si bien los viajeros no tuvieron un interés particular en las mujeres americanas como objeto de observación, asentaron ciertos rasgos, gestos y actitudes que les parecieron llamativos, gráciles, seductores e incluso descarados. ¿Sus razones? Baeza atisba que se los extranjeros resultaban llamativos, excéntricos y ofrecían la posibilidad de desplegar ante ellos sus bienes y atributos. ${ }^{76}$

En una misiva al virrey de la Croix, fechada el 5 de mayo de 1786, don Ambrosio O'Higgins, da cuenta de la llegada de la expedición de La Pérouse y afirma haberse esmerado "en atender y servir al Comandante de ellas", ${ }^{77}$ Es decir, los viajeros franceses habían sido recibidos, por órdenes oficiales, con gestos amistosos por parte de las autoridades chilenas, así como por parte de los habitantes de Concepción, tanto hombres como mujeres que hicieron el acopio de víveres. No obstante, sólo las expresiones afables de éstas últimas llamaron la atención de La Pérouse para quedar

\footnotetext{
${ }^{71}$ La Pérouse 68.

${ }^{72}$ La Pérouse 70.

${ }^{73}$ La Pérouse 70.

${ }^{74}$ Rafael Baeza Sagredo, "Entre la hospitalidad y la seducción.: la sociedad chilena y los viajeros ilustrados", en Gonzalbo Aizpuru, Pilar y Bazant, Mílada (eds.), Tradiciones y conflictos: Historias de la vida cotidiana en México e Hispanoamérica (México: El Colegio De México, 2007), 291-316.

${ }^{75}$ Frezier también ofrece descripciones de las mujeres indígenas de Chile. Resalta sus rasgos físicos, su vestimenta, que es diferente en las ciudades que en los espacios rurales (donde -afirma- suelen tener los senos descubiertos. También enumera algunas de las actividades económicas a las que se dedican como la producción de chica y harinas. Frezier 98-101.

${ }^{76}$ Baeza Sagredo 299.

${ }^{77}$ Archivo Histórico Nacional de España (AHN), Estado, 4289, exp.1, (Madrid, 15 de mayo de 1786). "Expedientes relativos al viaje alrededor del mundo del conde de La Pérouse y a los establecimientos rusos en la costa occidental de América al Norte de California".
} 
asentadas en su relato de viaje. Las mujeres de Concepción, independientemente de su estatus, se mostraban, intentaban complacer, ofrecían atenciones y hospitalidad. En contraste con las mujeres indígenas en California que los ignoraron o las de Brasil que les rehuyeron, las damas de la sociedad de Concepción se esforzaron por atraer la atención de los forasteros, construyendo así una imagen del deseo, que los franceses detectaron y que apreciaron, pero también condenaron.

Finalmente cabe señalar que el viajero menciona tangencialmente a las mujeres cautivas como parte de los estragos cometidos por los salvajes que masacraban a hombres y niños. Si bien este tema ha sido ampliamente estudiado por la historiografía de la frontera chilena, la ausencia de mayores detalles al respecto en el relato de La Pérouse puede atribuirse a la falta de testimonios directos al respecto e incluso al contexto de negociación que, para ese momento, encabezaba O'Higgins. Después de cuatro días de lluvias, 19 de marzo de 1786, la expedición de La Pérouse salió de Concepción hacia la isla de Juan Fernández, pasó por la isla de Pascua las islas Sandwich y llegó a Alaska en junio del mismo año.

\section{Monterrey, California: el castigo corporal y las mujeres indias}

Después de un incidente en el que pierde a una veintena de hombres, la expedición de La Pérouse llegó a Monterrey, California el 14 de septiembre de 1786. Ahí detectó la pequeña fuerza naval que, por órdenes del virrey de la Nueva España, resguardaba el puerto. El comandante Pedro Fagés había recibido órdenes de atenderlos y lo hizo proveyéndoles de víveres. A diferencia de los dos espacios fronterizos que hemos tratado anteriormente, en California la frontera estaba dominada por el sistema misional. ${ }^{78}$ Para cuando desembarcó La Pérouse en las cercanías de Monterrey, las misiones se encontraban a cargo de frailes franciscanos y la más cercana al puerto era la de San Carlos. Los padres se acercaron a darles la bienvenida y ofrecieron proporcionarle la información relativa al gobierno de las misiones y de todo aquello que despertara su interés. ${ }^{79}$

Después de haber sido recibidos con cierta fastuosidad, el presidente de las misiones condujo a los viajeros hacia el altar principal, pero, antes de entrar a la Iglesia, atravesaron una plaza donde los indios de ambos sexos estaban alineados. "Su semblante no revelaba ninguna sorpresa e incluso nos hizo dudar si seríamos objeto de su conversación durante el resto del día." ${ }^{80}$ (Imagen 2) A diferencia de la isla de Santa Catarina y de la bahía de la Concepción, las mujeres descritas por Pérouse en Monterrey son indígenas en medio de un proceso de transformación cultural y

\footnotetext{
${ }^{78}$ Alberto Lancaster Jones Verea, "La evangelización de la Alta California. Resumen sobre las misiones franciscanas de California", Alma Mater, 1 (1992): 75-95. Bernabéu Albert, Salvador y Ortega Soto, Martha. "Indios y franciscanos en la construcción de la Alta California", en García Cruzado, Eduardo (coord.) Actas de las Jornadas de Historia sobre el Descubrimiento de América: Jornadas IV, V y VI (Sevilla: Universidad Internacional de Andalucía, 2011), 405-434.

${ }^{79}$ La Pérouse 260.

${ }^{80}$ La Pérouse 261.
} 
subordinadas en todas sus prácticas a la disciplina impuesta por los religiosos. La nula interacción entre Pérouse y las mujeres indígenas de San Carlos define de un modo particular las observaciones que hace de ellas. Si en los casos anteriores las reflexiones que le detonan las mujeres están vinculadas a su relación con los varones, en este caso, la marginalidad de la agencia femenina se acentúa aún más en el relato de La Pérouse, pues su escrutinio se centra en el proyecto misional, sus logros y sus yerros. Las mujeres sólo son objeto de sus, más o menos atinadas, políticas.

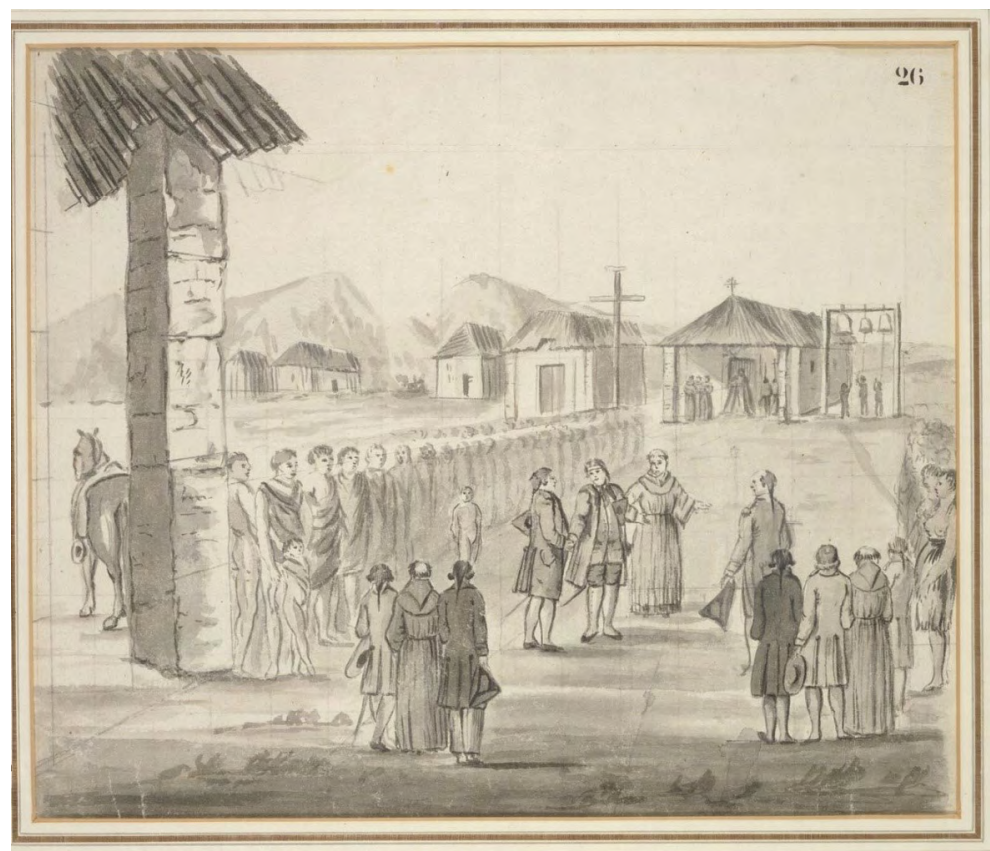

Imagen 2. Recibimiento a la Pérouse en California, 1786

Fuente: Cardero, José, The reception of Jean-François de la Perouse at Mission Carmel in 1786, California. UC Berkeley, Bancroft Library, Robert B. Honeyman, Jr. Collection of Early Californian and Western American Pictorial Material, BANC PIC 1963.002:1311—FR. http://content.cdlib.org/ark:/13030/ tf509nb5m2/?order $=1$

Además de la descripción de la rutina cotidiana de los indios, de algunos alimentos como el atole y el pozole, La Pérouse narra en su diario de viaje las actividades exclusivas de las mujeres, entre las que se encuentran el cuidado del hogar, de sus hijos, la cría de pollos y tostar y triturar el grano, "una tarea muy lenta y laboriosa porque su único método era hacerlo sobre una piedra con un rodillo, más o menos como se hace con el chocolate en Europa". Al atestiguar la rusticidad de la técnica de trituración, el señor de Paul Antoine de Langle, el segundo de a bordo de la expedición, decidió entregar su molino a los misioneros. La Pérouse aseguró que "sería difícil prestarles un mayor servicio; cuatro mujeres harán ahora el trabajo de 
cien, y quedará tiempo para hilar la lana de sus rebaños y fabricar telas rústicas." ${ }^{81}$ En este sentido, reclama que el celo religioso de los misioneros los había hecho renuentes a la introducción de técnicas y oficios que impulsarían en las misiones una vida más edificante y reitera una de las preocupaciones más constantes del francés: incentivar la producción y la manufactura.

En cuanto a la descripción de los vínculos familiares, a juicio de la Pérouse, las mujeres fueron beneficiadas al prohibirse la poligamia, pues "adquirieron la ventaja de ser cuidadas exclusivamente por un solo hombre", mientras que para los hombres esto significó un profundo sacrificio. Desde su perspectiva, la imposición del modelo garantizaba a las mujeres una suerte de derecho, mientras que la misma disposición atentaba contra una libertad masculina. Sobre la sexualidad femenina, Pérouse apunta que, durante la noche, se encerraba a las muchachas mayores de nueve años y durante el día eran vigiladas por las matronas con el fin de preservar su virtud. Sin embargo -dice Pérouse- hemos visto a varias mujeres con grilletes por haber violado la norma conyugal. ${ }^{82}$ En cuanto a la vestimenta de las mujeres, dice que consistía en un abrigo de piel de venado mal curtida y que su único adorno es un delantal pequeño y una falda de piel que les cubre la cintura y llega hasta la mitad de la pierna. ${ }^{83}$ En contraste con la fastuosidad de los vestidos de las mujeres de Concepción, en las misiones insiste en la precariedad de todos sus enseres.

Aunque sus observaciones sobre las misiones y los frailes fueron generalmente positivas, en varios aspectos "encontró incompatible la teocracia de la misión con los derechos naturales del hombre". ${ }^{84}$ Por un lado, denunció el carácter miserable de las cincuenta chozas que servían de alojamiento a setecientas cuarenta personas, así como la insuficiencia de la dieta. Por otro lado, su denuncia más álgida giraba en torno a los castigos. "Lo decimos con pena, hemos visto hombres y mujeres en yerros y otros en el bloc". ${ }^{85}$ También le extrañaba la rigurosidad con la que se perseguían pecados que en Europa no se sancionaban, pero lo que más llamó su atención fue la distinción en la administración del castigo de acuerdo con el género:

Las mujeres nunca son azotadas en la plaza pública, sino en lugar cerrado y bastante alejado, quizás para que sus gritos no despierten una compasión demasiado intensa, que podría llevar a los hombres a rebelarse; estos últimos, por el contrario, se exponen a la mirada de todos sus conciudadanos, para que su castigo sirva de ejemplo. ${ }^{86}$

\footnotetext{
${ }^{81}$ La Pérouse 267.

${ }^{82}$ La Pérouse 270.

${ }^{83}$ La Pérouse 271.

${ }^{84}$ Archibald Robert, "Indian Labor at the California Missions Slavery or Salvation?”, en The Journal of San Diego History, 24, 2 (1978).

${ }^{85}$ La Pérouse 263. El bloc era una especie de viga con un agujero y una bisagra de hierro dónde se metía la pierna del preso y, una vez dentro, se cerraba con un candado.

${ }^{86}$ La Pérouse 268.
} 
La Pérouse alcanza a distinguir los matices de la ejecución de las sanciones revelando la existencia de una economía del castigo dentro de las misiones en la Alta California. Es decir, las penas corporales formaban parte del repertorio de técnicas para corregir a los indios dentro de las misiones, pero el castigo no tenía ni los mismos objetivos ni las mismas consecuencias para los indios que para las indias. Por un lado, la segregación de la población femenina soltera se había institucionalizado en las misiones como dispositivo de control sobre sus cuerpos para evitar tratos sexuales fuera de los estándares aprobados. De este modo, la transgresión a esas normas atentaba contra uno de los pilares del orden misional, pues el desarraigo de prácticas como la poligamia había sido nodal para la desestructuración de las de las poblaciones indígenas. Por otro lado, la participación de las mujeres en la esfera productiva requería de un disciplinamiento constante pues las labores que desempeñaban eran arduas y laboriosas, pero, sobre todo, estaban vinculadas a la reproducción social. Finalmente, el castigo como mecanismo didáctico para evitar el incumplimiento de los deberes cristianos estuvo vinculado tanto a la coerción de la mano de obra como al cuidado del orden moral y religioso. ${ }^{87} \mathrm{Y}$, a pesar de que, para finales del siglo XVIII, la tendencia en Europa se dirigía hacia la abolición del castigo físico, en los confines americanos la prerrogativa se mantenía

\section{Conclusiones}

Tradicionalmente, tanto las fronteras como los oficios del mar han sido concebidos como universos masculinos e inherentemente conflictivos. A pesar de que esta esquematización, ha sido recientemente cuestionada, su concepción como espacios mararcados por la violencia, el riesgo, la guerra, el aislamiento y el desamparo, invisibilizó el rol de las mujeres. Por ello, entresacar de las fuentes coloniales las menciones a las mujeres, sus prácticas y sus sociabilidades, por escuetas que parezcan, implican un vuelco a esa imagen. Así lo han demostrado estudios recientes que destacan la labor de las mujeres como embajadoras en los tratados de paz y parlamentos, como rehenes y garantes de la estabilidad en las relaciones hispano indígenas, como comerciantes, querellantes, traductoras y transgresoras ${ }^{88}$ No obstante, el número de trabajos dedicados a las mujeres y a sus roles en espacios fronterizos, fuera del cautiverio, son mucho menores que aquellos dedicados a las mujeres en los espacios urbanos y plenamente incorporados al dominio colonial.

\footnotetext{
${ }^{87}$ Para un análisis del papel del castigo corporal en las misiones de otro espacio colonial hispano véase Querleri, Lía. "Castigos físicos y control de los cuerpos: mujeres guaraníes, trabajo y poder colonial”, Temas americanistas, 40 (2018): 239-264.

${ }^{88}$ La bibliografía al respecto es amplia. Refiero solo algunos trabajos paradigmáticos. Roulet, Florencia. "Mujeres, rehenes y secretarios: Mediadores indígenas en la frontera sur del Río de la Plata durante el período hispánico", en Colonial Latin American Review, vol. 18, núm. 3, 2009, pp. 303-337. Cerda Pincheira, Patricia. "Las mujeres en la sociedad fronteriza del Chile colonia", en Jahrbuch für Geschichte Lateinamerikas, [Anuario de Historia de América Latina], 26 (1989), 127-171. Yessica González, "Malas mujeres, adúlteras, criminales y transgresoras dentro de un espacio regional. Concepción, siglo XIX", en González, Yessica (ed.), Mujeres: olvidos y memorias en los márgenes. Chile y América, siglos XVII-XXI (Santiago: Universidad de la Frontera, 2020), 189-212.
} 
Las tres fronteras visitadas por el conde de La Pérouse tienen condiciones disimiles que determinan el margen de acción de las mujeres. La ausencia del espacio público de las mujeres de Santa Catarina se asocia, por un lado, a los "celos" de los varones, pero por otro, a la experiencia que dicha isla tenía de ataques previos en los que las mujeres habían adquirido un valor simbólico. Al dañarlas, violarlas o cautivarlas, el enemigo menoscababa a los varones del lugar, cuestionaba su capacidad para defenderlas y de ese modo se mostraba la fortaleza de un bando sobre el otro. Tomar refugio ante la llegada de los forasteros era, al menos desde un siglo antes, una práctica común de las mujeres, que más allá de la imagen de indefensión, remite a un recurso de defensa aprendido y compartido por todas ellas y, al parecer, por generaciones. Aun así, es necesario apuntar que el testimonio de La Pérouse y de Frezier comparten un ideal de lo femenino asociado a la hospitalidad y la afabilidad; es decir extrañan el recibimiento cordial y la atención que las mujeres de otros espacios les habían brindado. Así es posible entender la discrepancia entre el relato del diario de viaje y la imagen que apareció en el Atlas du Voyage de la Pérouse, después de su muerte en la que esta idealización es más evidente. Queda pendiente el análisis sistemático de las imágenes y su proceso de publicación como obra independiente de los diarios.

En consonancia con los relatos de otros viajeros que habían visitado Bahía de la Concepción, La Pérouse dedicó especial cuidado a la descripción de las vestimentas, los gestos y el carácter de las mujeres. Dada la mayor interacción que pudo tener con diversos grupos de mujeres en fiestas y bailes, sus observaciones se concentraron en la valoración moral de los comportamientos, pero no así de su nivel intelectual. A pesar de hacer una generalización de la población como poco inclinada al trabajo, Pérouse no hace alusión al trabajo femenino ni a su incorporación a la estructura productiva. Una de las riquezas de esta fuente, es que al haber tratado principalmente a mujeres mestizas y criollas de altos estratos, tenemos noticia de las prácticas y las sociabilidades cotidianas de estos grupos. Y es que, si bien las cautivas han tenido un papel central en el análisis de las agencias femeninas en esta frontera, preguntar por los roles domésticos y de convivencia de otras mujeres puede desembocar en un análisis puntual sobre la flexibilidad de los marcos normativos de la sexualidad y la sociabilidad femenina en espacios fronterizos.

Finalmente, la descripción que hace de las mujeres indígenas de la misión de San Carlos se inscribe en el análisis y crítica que hace del sistema misional. Sus apreciaciones responden, en primera instancia, a la casi nula interacción directa que tuvo con ellas y a la indiferencia de los indios ante su llegada, asunto que, aunque tangencialmente, menciona Pérouse, pues contrasta con sus otras experiencias. En este caso, su evaluación se centra en el trabajo de las mujeres, en la precariedad de sus condiciones de vida, y en el régimen de castigos corporales que coadyubaba a mantener la disciplina en aquellos establecimientos, así como las diferencias de género en los procedimientos de sanción que los frailes habían diseñado para evitar levantamientos y rebeliones. 
En la literatura de las expediciones científicas, como en la documentación oficial emanada de la administración y defensa de las fronteras, la escasez de menciones a mujeres es una constante. En los relatos de viaje del siglo XVIII analizados, la representación de las mujeres suele estar vinculada con la descripción de prácticas específicas, ya sea de trabajo, familiares y de sexualidad, o a transgresiones denunciadas y condenadas. Esto responde a que en la enorme mayoría de los casos estos testimonios fueron hechos por varones que no consideraban a las mujeres como un objeto de observación en sí mismo ni como sujetos que capaces de generar prácticas o conocimientos de trascendencia para la sociedad. La descripción de las mujeres siempre estuvo en relación con y como complemento de las prácticas masculinas; no por ser sujetos de acción propia. A pesar de que la Ilustración había permitido a ciertas mujeres europeas incorporarse a los debates intelectuales sobre la igualdad de su condición, a inaugurar nuevas formas de sociabilidad y a ocupar e incluso presidir ciertos espacios públicos, en estas obras lo femenino se concebía aun estrictamente ligado al ámbito de lo doméstico y sólo atraía la atención de los expedicionarios de forma excepcional. Para subvertir las narrativas masculinas de los espacios de frontera y rescatar, en la medida de lo posible, la agencia femenina es necesaria una perspectiva que atienda aquellos indicios que se filtran dentro de estos relatos.

Las informaciones que Jean-François de Galaup, conde de La Pérouse, asentó en sus diarios de viaje sobre las mujeres de las fronteras americanas de la isla de Santa Catarina, la Bahía de Concepción en Chile y la misión franciscana de San Carlos en la Alta California aparecen ligadas a la descripción del espacio, de la estructura política y social y de las costumbres de los pobladores. No obstante, en cada caso las descripciones nos permiten atisbar las condiciones de vida específicas de las mujeres y sus márgenes de acción. Este cotejo, nos permite concluir que la diversidad de condiciones que vivieron las mujeres de las fronteras en América impide generalizarlas dentro de un mismo concepto, pues si bien, muchas de ellas, al vivir en espacios de conflicto, compartieron la condición de vulnerabilidad, sus posibilidades de agencia estaban directamente vinculadas al lugar que ocupaban dentro de una sociedad altamente jerarquizada como la colonial.

\section{Bibliografía}

\section{Fuentes Primarias}

\section{Archivos}

Archivo Histórico Nacional (AHN), Estado, 4289, exp.1. (Madrid, 15 mayo de 1786).

\section{Libros}

Byron, John. Relato del honorable John Byron (comodoro de la última expedición alrededor del mundo). Que contiene una esposición de las grandes penurias sufridas por él i sus compañeros en la costa de la Patagonia desde el año 1740 
hasta su arribo a Inglaterra en 1746 con una descripción de Santiago de Chile $i$ de las usanzas $i$ costumbres de sus habitantes i ademas una relacion de la pérdida de la fragata Wager de la escruadra del Almirante Anson. Santiago de Chile: Imprenta Cervantes, 1901. Traducido de la primera edición inglesa de 1768 por José Valenzuela.

Cook, James. The Three Voyages Of Captain James Cook Round The World. 7 v. London: A. \& R. Spottiswoode, 1821.

Frezier, Amédée François. Relation du voyage de la mer du Sud aux cotes du Chili, du Perou, et du Bresil, fait pendant les années 1712, 1713 \& 1714. T. 1, Amsterdam; Pierre Humbert, 1717.

La Condamine, Charles-Marie de. Relation abrégée d'un voyage fait dans l'interieur de l'Amérique Méridionale. Depuis la côte de la Mer du Sud, jusqu'aux côtes du Brésil \& de la Guiane, en descendant la riviere des Amazones; lûe à l'assemblée ces, le 28. avril 1745. Par M. de La Condamine. Avec une carte du Maragnon levée par le même. París: Veuve Pissot. 1745.

La Pérouse, Jean-François de Galaup. Relation abrégée du voyage de La Pérouse pendant les années 1785, 1786, 1787 et 1788. Leipzig: s.e. 1799. https://archive. org/details/cihm_45471/page/n5/mode/2up

La Pérouse, Jean-François de Galaup. [redactado por Milet-Mureau, Louis Antoine] Voyage de La Pérouse autour du Monde, t. II. París: Imprimerie de la République, 1797.

La Pérouse, Jean-François de Galaup. Atlas du voyage de La Pérouse, París: Imprimerie de la République, 1797. https://open.library.ubc.ca/collections/ bcbooks/items/1.0365994\#p6z-7r0f

Malaspina, Alessandro. Viaje político-cientifico alrededor del mundo por las corbetas Descubierta y Atrevida al mando de los capitanes de navio D. Alejandro Malaspina y Don José de Bustamante y Guerra desde 1789 a 1794 / publicado con una introducción por Don Pedro de Nova y Colson. Madrid: Imprenta de la viuda e hijos de Abienzo, 1885.

Ulloa, Antonio de. Noticias americanas: entretenimientos phisico-historicos sobre la América meridional, y la septentrional oriental, comparacion general de los territorios, climas, y produciones en las tres especies, vegetales, animales, y minerales: con relacion particular de las petrificaciones de cuerpos marinos de los indios naturales de aquellos paises, sus costumbres y usos: de las antiguedades: discurso sobre la lengua, y sobre el modo de pensar en que pasaron los primeros pobladores. Madrid: Don Francisco Manuel de Mena, 1772. 
Las mujeres de las fronteras americanas en la expedición cientifica de Jean-François de......

Bougainville, Louis Antoine de. Viaje alrededor del mundo por la fragata del Rey La "Boudeuse" y la fusta la "Estrella" en 1767, 1768 y 1769. 2 v., traducido del francés por Josefina Gallego de Dantín. Madrid: Editorial Calpe, 1921.

\section{Fuentes secundarias}

\section{Libros}

Amaya, José Antonio. Celestino Mutis y la expedición botánica. Madrid: Debate, 1986.

Azara, Félix. Viajes por la América Meridional. Madrid: Espasa Calpe, 1969.

Baratas Díaz, Luis Alfredo (coord.), Memorias de la Real Sociedad Española de Historia Natural, t. 3. Madrid: Real Sociedad Española de Historia Natural, 2004.

Bellec, François. La Genereuse et Tragique Expedition Laperouse. Rennes: OuestFrance Université, 1985.

Brading, David. Orbe indiano. De la monarquía católica a la República criolla, 1492 1867. México: Fondo de Cultura Económica, 2003.

Brosse, Jacques, Les tours du monde des explorateurs. Les grands voyages maritimes, 1764-1843. París: Bordas, 1983.

Calatayud, María de los Ángeles. Catálogo de las expediciones y viajes científicos españoles a América y Filipinas (siglos XVIII y XIX). Madrid: Consejo Superior de Investigaciones Científicas, Museo Nacional Ciencias Naturales, 1984.

Dunmore, John. La Pérouse. Explorateur du Pacifique. París: Payot, 1986.

Gaziello. Catherine. L'expédition de Lapérouse (1785-1788), réplique française aux voyages de Cook. París: La Documentation française, 1983.

González Claverán, Virginia. La expedición científica de Malaspina en Nueva España: 1789-1794. México: El Colegio de México, 1988.

Hernández Ascencio, Raúl. El matemático impaciente. La Condamine, las pirámides de Quito y la ciencia ilustrada (1740 -1751). Lima: Instituto de Estudios Peruanos, Instituto Francés de Estudios Andinos, 2008.

Juan, Jorge. Relacion historica del viage a la America Meridional hecho de orden de S. Mag. para medir algunos grados de meridiano terrestre y venir por ellos en conocimiento de la verdadera figura y magnitud de la tierra, con otras observaciones astronomicas y phisicas. vol. 4. Madrid: Antonio Marin, 1748. 
Nieto Olarte, Mauricio. Remedios para el imperio. Historia natural y apropiación del Nuevo Mundo. Bogotá: Instituto Colombiano de Antropología e Historia, 2000.

Pelayo López, F. (Ed.), Pehr Lofling y la expedición al Orinoco: 1754-1761, Madrid: CSIC, 1990.

Real Comisión de Guantánamo. Cuba ilustrada. La Real Comisión de Guantánamo 1796-1802. Madrid: Sociedad Estatal Quinto Centenario, Ministerio de Agricultura Pesca y Alimentación, Museo Naval Madrid, Real Jardin Botánico, Ministerio de Obras Públicas y Transportes, Lunwerg editores, 1991.

Ridley, Glynis. The Discovery of Jeanne Baret: a story of science, the high seas, and the first woman to circumnavigate the world. Nueva York: Harper Collins, 2011.

San Pío Aladrén, María Pilar de (coord.). La expedición de Juan de Cuéllar a Filipinas. Madrid: Consejo Superior de Investigaciones Científicas, CSIC, Real Jardín Botánico, Lunwerg, Caja Madrid, 1997.

\section{Capítulos de Libro}

Alburquerque García, Luis. "Los 'libros de viaje’ como género literario”, en Lucena, Manuel y Pimentel, Juan (eds.), Diez estudios sobre literatura de viajes. Madrid: CSIC, 2006.

Baeza, Rafael Sagredo. "Entre la hospitalidad y la seducción: La sociedad chilena y los viajeros ilustrados", en Gonzalbo Aizpuru, Pilar y Mílada Bazant (eds.), Tradiciones y Conflictos: Historias De La Vida Cotidiana En México e Hispanoamérica. Ciudad de México: El Colegio De México, 2007. www.jstor.org/ stable/j.ctv47wbxj.13.

Barnés, Mónica. "Frezier, Amédée François (1682-1773)", en Pillsbury, Joanne (ed.), Fuentes documentales para los estudios andinos 1530-1900, v. II. Lima: Center for Advanced Study in the Visual Arts (CASVA), National Gallery of Art and Pontificia Universidad Católica del Perú, 2016.

Bernabéu Albert, Salvador y Ortega Soto, Martha. "Indios y franciscanos en la construcción de la Alta California", en García Cruzado, Eduardo (coord.) Actas de las Jornadas de Historia sobre el Descubrimiento de América: Jornadas IV, $V$ y VI. Sevilla: Universidad Internacional de Andalucía, 2011.

Bolufer Peruga, Mónica. "Las mujeres en la cultura de la Ilustración”, en Martínez, Enrique y de Pazzis, Magdalena (eds.), Ilustración, ciencia y técnica en el siglo XVIII. Valencia: Universidad de Valencia, 2008.

González, Yessica. "Malas mujeres, adúlteras, criminales y transgresoras dentro de un espacio regional. Concepción, siglo XIX”, en González, Yessica (ed.), Mujeres: 
olvidos y memorias en los márgenes. Chile y América, siglos XVII-XXI. Santiago: Universidad de la Frontera, 2020, 189-212.

Hilton, Sylvia. "El límite noroccidental del imperio hispanoamericano 1513-1784", en Abbad y Lasierra, Íñigo. Descripción de las costas de California. Madrid: Consejo Superior de Investigaciones Científicas, Instituto “Gonzalo Fernández de Oviedo", 1981.

Rodríguez Nozal Raúl. "La obra impresa del programa expedicionario español en América”, en Ruiz, Hipólito., Relación del viaje hecho a los reinos del Perú y Chile por los botánicos y dibujantes enviados por el Rey para aquella expedición, extractada de los diarios por el orden que llevó en éstos su autor, Introducción, transcripción y notas de Raúl Rodríguez Nozal y Antonio González Bueno. Madrid: Consejo Superior de Investigaciones Científicas, 2007.

\section{Artículos de revista}

Boccara, Guillaume. "El poder creador: tipos de poder y estrategias de sujeción en la frontera sur de Chile en la época colonial", en Anuario De Estudios Americanos, 56, 1 (1999).

Cerda Pincheira, Patricia. "Las mujeres en la sociedad fronteriza del Chile colonia", en Jahrbuch für Geschichte Lateinamerikas, [Anuario de Historia de América Latina], 26 (1989).

Costa, Maria de Fátima. "Viajes en la frontera colonial. Historias de una expedición de límites en la América Meridional (1753-1754)", Anales del Museo de América, 16 (2009).

Da silva, Augusto. "Os 'Povoadores' da ilha de Santa Catarina: Hierarquia social, trabalho livre e conflitos (1748-1800)", Revista Territórios \& Fronteiras, 8, 2 (2015).

Dos Santos Mendes, Jeferson. "Para defender é preciso fortificar: as defesas da Ilha de Santa Catarina durante o século XVIII", Fronteiras Revista de História, 21, 36 (2018).

Escudero, Lola. "Viajes, ciencia e ilustración. las expediciones científicas españolas en el siglo XVIII”, Boletín de la Sociedad Geográfica Española, 22 (2005).

Fauque Danielle. «Il y a deux cents ans: l'expédition Lapérouse», en Revue d'histoire des sciences, t. 38, 2 (1985).

Gándara, Natalia. "Representaciones de un territorio. La frontera mapuche en los proyectos ilustrados del reino de Chile en la segunda mitad del siglo XVIII", Historia Crítica, 59 (2016). 
George, Sam. "The cultivation of the female mind: enlightened growth, luxuriant decay and botanical analogy in eighteenth-century texts", History of European Ideas, 31, 2 (2005).

González, Yessica. "Indias blancas tierra adentro. El cautiverio femenino en la Frontera de la Araucanía, siglos XVIII y XIX", Anuario Colombiano de Historia Social y de la Cultura, 43, 2 (2016).

Lobato, Tatiana. "Botánica: una ciencia femenina en Latinoamérica", La ventana, 6, 48 (2018).

Maldonado Polo, José Luis. “La expedición botánica a Nueva España, 1786-1803: el Jardín Botánico y la Cátedra de Botánica”, en Historia Mexicana, 50 (2000).

Matute Corona, María. “Cádiz y la expedición de límites al Orinoco (1754-1761): Pedro Virgili y Pehr Löfling”, Revista Hispano Americana, 8 (2018).

Montoya, Fredy. "Controversias epistemológicas en torno a los viajeros del nuevo Reino de Granada, siglo XVIII, en Telar, s/v, 11.12 (2014).

Ortiz-Troncoso, Omar. "La Pérousse explorador Del Pacifico", Revista de Marina, 787 (1988).

Paredes, Rogelio. "Guerra en los libros. La competencia colonial del siglo XVIII entre Gran Bretaña y Francia en los libros del Museo Etnográfico de Buenos Aires (1690-1800)", en Avances del Cesor, año VIII, núm 8, 2011. https://core.ac.uk/ download/pdf/162567802.pdf

Pinzón Rios, Guadalupe, “El Pacifico novohispano a partir del Mapa de la América Septentrional de 1754”, en Estudios Jalisciences, 107 (2017).

Puig-Samper, Miguel Ángel. "Las expediciones científicas españolas en el siglo XVIII”, en Canelobre, núm. 57, 2011. https://www.casadevelazquez.org/fileadmin/ fichiers/investigacion/Ateliers/Conocer/Las_expediciones_cient $\% \mathrm{C} 3 \% \mathrm{ADficas}$ espa\%C3\%B1olas_en_el_siglo_XVIII.pdf

Querleri, Lía. “Castigos físicos y control de los cuerpos: mujeres guaraníes, trabajo y poder colonial”, Temas americanistas, 40 (2018).

Robert Archibald. "Indian Labor at the California Missions Slavery or Salvation?", en The Journal of San Diego History, 24, 2, 1978. https://sandiegohistory.org/ journal/1978/april/labor/

Roulet, Florencia. "Mujeres, rehenes y secretarios: Mediadores indígenas en la frontera sur del Río de la Plata durante el período hispánico", en Colonial Latin American Review, 18, 3 (2009). 
Torres Santo Domingo, Marta. "Los viajes del capitán Cook en el siglo XVIII: una revisión bibliográfica", en Biblio3W, Revista Bibliográfica de Geografía y Ciencias Sociales, VIII, 441 (2003).

Vásquez de Espinoza, Antonio. Descripción de Reino de Chile. Santiago: Editorial Blas Cañas, (1986).

Whitaker, Arthur. “Antonio De Ulloa.”, en The Hispanic American Historical Review, 15, 2 (1935).

Zamudio Valera, Graciela. "Las expediciones botánicas a América en el siglo XVIII". Ciencias, 29, (1993).

\section{Tesis, ponencias y otros inéditos}

Da silva, Augusto. A Ilha de Santa Catarina e sua Terra Firme. Estudo sobre o governo de uma capitania subalterna (1738-1807). (Tesis de posgrado) Universidad de São Paulo, 2007.

Rico Boledón, Óscar. La ocupación española de Santa Catarina (1777-1778). Una isla brasileña para Carlos III, (Tesis de doctorado), Universidad de Salamanca, 2013.

\section{Publicaciones de internet}

Azara, Félix, Diario de la navegación y reconocimiento del río Tebicuari, https:// biblioteca.org.ar/libros/131007.pdf (25

Real Expedición Botánica del Nuevo Reino de Granada. Flora de la Real Expedición Botánica del Nuevo Reino de Granada, Madrid: Gobiernos de España y de Colombia entre los Institutos de Cultura Hispánica de Madrid y Bogotá, 2010. http://bibliotecadigital.aecid.es/bibliodig/es/consulta/registro.cmd?id=3148

Tamagnini, Marcela y Pérez Zavala, Graciana. "Mujeres de frontera: entre el cautiverio y el estigma” en IV Congreso Chileno de Antropología, Santiago de Chile, Colegio de Antropólogos de Chile A. G, 2001, https://www.aacademica. org/iv.congreso.chileno.de.antropologia/102 